\title{
Resveratrol modulates the apoptosis and autophagic death of human lung adenocarcinoma A549 cells via a p53-dependent pathway: Integrated bioinformatics analysis and experimental validation
}

\author{
YAMENG FAN $^{1 *}$, JIAQIAO LI $^{1 *}$, YUXUAN YANG $^{2 *}$, XIAODAN ZHAO ${ }^{2}$, YAMEI LIU $^{1}$, \\ YUDE JIANG $^{1}$, LONG ZHOU ${ }^{1}$, YANG FENG ${ }^{1}$, YAN YU ${ }^{1}$ and YILONG CHENG ${ }^{3}$ \\ ${ }^{1}$ School of Public Health, ${ }^{2}$ School of Basic Medicine, and ${ }^{3}$ School of Science, \\ Xi'an Jiaotong University, Xi'an, Shaanxi 710061, P.R. China
}

Received December 26, 2019; Accepted July 22, 2020

DOI: 10.3892/ijo.2020.5107

\begin{abstract}
Resveratrol (RSV) has been reported to exhibit cytotoxic activity in multiple types of malignant cells; however, the mechanisms underlying the antitumor effects of RSV in non-small-cell lung cancer (NSCLC) cells remain undetermined. Combining bioinformatics analysis with experimental validation, the present study aimed to examine the effects of RSV on the apoptosis and autophagy of A549 NSCLC cells, and to determine the potential underlying molecular mechanisms. Bioinformatics analysis was used to determine the differentially expressed genes (DEGs) and identify the enriched biological functions and pathways associated with these DEGs
\end{abstract}

Correspondence to: Professor Yan Yu, School of Public Health, Xi'an Jiaotong University, 76 West Yanta Road, Xi'an, Shaanxi 710061, P.R. China

E-mail: yuyanpaper@yeah.net

Professor Yilong Cheng, School of Science, Xi'an Jiaotong University, 76 West Yanta Road, Xi'an, Shaanxi 710061, P.R. China E-mail: mhxy54621@163.com

${ }^{*}$ Contributed equally

Abbreviations: NSCLC, non-small-cell lung cancer; RSV, resveratrol; MTT, 3-(4,5-dimethylthiazol-2-yl)-2,5-diphenyltetrazolium bromide; MDC, monodansylcadaverine; TEM, transmission electron microscope; PFT- $\alpha$, pifithrin- $\alpha$; 3-MA, 3-methyladenine; PCD, programmed cell death; GEO, Gene Expression Omnibus; GO, Gene Ontology; KEGG, Kyoto Encyclopedia of Genes and Genomes; DAVID, Database For Annotation Visualization and Integrated Discovery; LIMMA, Linear Models for Microarray; AC, adenocarcinoma; SCC, squamous cell carcinoma; OD, optical density; IOD, integrated option density; DEGs, differentially expressed genes; CC, Cellular component; BP, biological process; MF, molecular function

Key words: NSCLC, resveratrol, apoptosis, autophagy, bioinformatics following RSV treatment. Cell viability was determined by MTT assay, and flow cytometry and TUNEL assay were used to evaluate cell apoptosis. Monodansylcadaverine staining combined with a transmission electron microscope were used to evaluate the extent of autophagy. The expression levels of apoptosis-, autophagy-, or pathway-associated molecular markers were measured by reverse transcription-quantitative PCR and/or western blot analysis. By bioinformatics analysis, a total of 1,031 DEGs were identified in the RSV-treated A549 cells, which were enriched in apoptosis-, or autophagy-related biological functions and the p53 signaling pathway. In validation experiments, RSV significantly reduced cell viability and initiated apoptosis, with an increase in the number of apoptotic cells; it also upregulated cleaved caspase-3 expression and Bax expression, and downregulated the $\mathrm{Bcl}-2$ expression levels. Additionally, there was an increase in the accumulation of green dot-like structures, indicative of autophagic vesicles, observed under a fluorescence microscope, and an increase in the presence of autophagic vacuoles observed using a transmission electron microscope following RSV treatment. Furthermore, the expression levels of the autophagy-related proteins, LC3-II/LC3-I and Beclin-1, were increased and p62 expression was decreased. 3-methyladenine (3-MA), an inhibitor of autophagy, partially reversed the RSV-induced cytotoxic effects, but did not significantly alter the number of apoptotic cells. RSV elevated the p53 levels and decreased the phosphorylated (p-)Mdm2 and p-Akt levels. Pifithrin- $\alpha$, an inhibitor of p53, partially reduced RSV-induced apoptosis and autophagy. On the whole, the results of the present study demonstrated that RSV initiates the apoptosis and autophagic death of A549 cells via the activation of the p53 signaling pathway, further highlighting the potential of RSV for the treatment of NSCLC.

\section{Introduction}

Lung cancer is currently the leading cause of cancer-related mortality worldwide, and in China, it ranks first in both morbidity and mortality rates from malignant tumors (1). 
Non-small cell lung cancer (NSCLC) is the most common type of lung cancer, accounting for $\sim 85 \%$ of all lung cancer cases (2). Although significant progress has been achieved in surgery, radiotherapy and chemotherapy for tumor therapy, the 5 -year survival rate of patients with NSCLC remains $<20 \%$, as the majority of cases are often diagnosed at locally advanced or advanced stages, and patients may experience adverse effects from traditional therapies (3). Thus, there is an urgent need for the discovery of novel therapeutic targets and effective anticancer agents for the treatment of patients with NSCLC.

Natural resources are abundant, containing plentiful natural substances with potent antitumor efficacy (4). In recent years, these substances, such as oridonin and Celastrus orbiculatus have attracted attention worldwide due to their accessibility, and relatively low adverse effects $(5,6)$. Resveratrol (RSV), a plant polyphenol extracted from peanuts, grapes, mulberries, Polygonum cuspidatum and other dietary sources, was first reported in 1997 as an anti-promyelocytic leukemia agent (7). The anticancer properties of RSV have been demonstrated in several different types of cancer, including skin cancer, breast cancer, lung cancer and colorectal cancer, amongst others (8-11). However, the underlying molecular mechanisms require further study.

The initiation of programmed cell death (PCD) is a crucial regulatory mechanism of several anticancer agents in tumor cells and involves two major types, apoptosis and autophagy. Apoptosis, also known as type I PCD, is a cell suicide process, characterized by cell shrinkage, nuclear chromatin condensation and fragmentation, as well as by the formation of apoptotic bodies, and has long been considered the primary mechanism underlying anti-tumor activity (12). More recently, autophagy, a catabolic process involving the degradation of unwanted macromolecules and organelles, has gained increasing attention, and is considered a double-edged sword with regard to tumorigenesis, development and therapy; autophagy may be used as a survival mechanism induced during adverse conditions, or conversely, a mode of cell death known as autophagic cell death, also termed type II PCD (13). Numerous studies have suggested that RSV may exert its anticancer effects via the induction of cell apoptosis individually or jointly in various types of cancer (14-16). Furthermore, studies have also suggested that RSV may initiate cell autophagy accompanied with or without apoptosis $(17,18)$. A recent study demonstrated that RSV induced protective autophagy via the activation of SIRT1 in NSCLC (19), whereas other studies have shown that RSV-induced cell death is regulated through autophagy $(20,21)$. Due to the limitations and contradictory results of previous studies, the mechanisms underlying the effects of RSV on NSCLC associated with PCD require further study to clarify the mechanisms using integrated analysis.

Recently, increasing evidence has demonstrated that apoptosis and autophagy may be initiated via a common upstream signal, such as the AMPK/mTOR signaling pathway, PI3K/Akt/mTOR signaling pathway or p53 signaling pathway (22-24). The p53 pathway exerts different modulatory effects on cell growth, migration, apoptosis and autophagy in multiple types of tumor cells $(25,26)$. It has been reported that p53 accumulation results from a decrease in phosphorylated (p-)AKT-mediated Mdm2 phosphorylation, resulting in tumor suppression and providing immense potential in inducing cell death $(27,28)$. However, to the best of our knowledge, there are no studies available to date which have investigated the mechanisms through which the p53-dependent signaling pathway is integrated into RSV-induced apoptosis, as well as autophagy in NSCLC cells.

Therefore, by combining bioinformatics analysis and experimental validation, the present study examined the effects of RSV on the apoptosis and autophagy of p53 wild-type A549 NSCLC cells, and analyzed the potential underlying regulatory mechanisms of these processes, providing evidence for the possible use of RSV as a therapeutic agent for the treatment of NSCLC.

\section{Materials and methods}

Selection of the Gene Expression Omnibus (GEO) dataset. The GEO database was used to search for datasets exploring the association between RSV and NSCLC. The search terms used were as follows: Resveratrol AND (lung OR pulmonary OR respiratory) AND (cancer OR tumor OR neoplasm OR carcinoma OR 'non-small cell lung cancer' OR adenocarcinoma OR 'squamous cell carcinoma' OR NSCLC OR AC OR SCC). The organism was filtered by 'Homo sapiens'. The inclusion criteria were an original study and included microarray profiles or high-throughput sequencing. The exclusion criteria were the following: i) Reviews, meta-analyses, case reports or conference abstracts; ii) the absence of a control group; or iii) insufficient data.

Identification of differentially expressed genes. The datasets were pre-processed, normalized, $\log 2$-transformed and analyzed using the Linear Models for Microarray (LIMMA) of $R$ package (29). The DEGs were verified using a Bayes test based on Bayes' conditional probability, and expressed as a volcano plot and heatmap. $\mathrm{P}<0.05$ and a log fold change (FC) $>|1.2|$ were used as the cut-off criteria.

Enrichment analysis. Gene Ontology (GO) enrichment analysis $(30,31)$ and Kyoto Encyclopedia of Genes and Genomes (KEGG) pathway enrichment analysis (32) were both conducted performed using the Database for Annotation Visualization and Integrated Discovery (DAVID) version $6.8(33,34) . \mathrm{P}<0.05$ was considered to indicate a statistically significant difference.

Reagents. RSV, 3-methyladenine (3-MA), pifithrin- $\alpha$ (PFT- $\alpha$ ) and monodansylcadaverine (MDC) were purchased from Sigma-Aldrich; Merck KGaA. RPMI-1640 medium was purchased from HyClone; GE Healthcare. FBS was purchased from Biological Industries. Penicillin-streptomycin and trypsin were purchased from Gibco; Thermo Fisher Scientific, Inc. DMSO and MTT were purchased from MP Biomedicals, LLC. The Annexin V-fluorescein isothiocyanate (FITC)/propidium iodide (PI) apoptosis detection kit was purchased from 7Sea Pharmatech Co., Ltd. TRIzol ${ }^{\circledR}$ reagent was purchased from Ambion; Thermo Fisher Scientific, Inc. PrimeScript RT Master mix (cat. no. RR036) and TB Green Premix Ex Taq II (cat. no. RR820A) were purchased from Takara Bio, Inc. The primers were synthesized and purchased from Beijing AuGCT DNA-SYN Biotechnology Co., Ltd. The One step TUNEL apoptosis assay kit, DAPI, RIPA lysis buffer, an SDS-PAGE kit 
and bicinchoninic acid (BCA) protein assay kit were purchased from Beyotime Institute of Biotechnology. Primary antibodies against Bax, Bcl-2, cleaved caspase-3, LC3, Beclin-1, p62, p53, p-MDM2, Akt and p-Akt were purchased from Cell Signaling Technology, Inc. The primary antibody against pro-caspase-3 was purchased from Abcam. The primary antibody against GAPDH and the goat anti-rabbit horseradish peroxidase (HRP)-conjugated secondary antibody were purchased from ProteinTech. Immobilon western chemiluminescence HRP substrate was purchased from EMD Millipore.

RSV was dissolved in DMSO and stored at $-20^{\circ} \mathrm{C}$ at a concentration of $200 \mathrm{mM}$, PFT- $\alpha$ was dissolved in DMSO at a concentration of $40 \mathrm{mM}$, and 3-MA was dissolved in PBS at a concentration of $200 \mathrm{mM}$. All the stock solutions were diluted in RPMI-1640 medium to the required concentration. DMSO was used as a control for the entire study at a final concentration of $<0.1 \%$.

Cell line and cell culture. Human A549 NSCLC cells were purchased from The Cell Bank of Type Culture Collection of the Chinese Academy of Sciences and cultured in RPMI-1640 medium with $10 \% \mathrm{FBS}$ and $1 \%$ penicillin-streptomycin at $37^{\circ} \mathrm{C}$ in a humidified incubator with $5 \% \mathrm{CO}_{2}$.

Cell viability assay. MTT assays were performed to detect cell viability. Briefly, the A549 cells ( $1 \times 10^{4}$ cells/well) were seeded in a 96 -well plate for $24 \mathrm{~h}$, and incubated at $37^{\circ} \mathrm{C}$ with various concentrations $(0,25,50,100$ or $200 \mu \mathrm{M}) \mathrm{RSV}$ for different periods of time (24, 48 or $72 \mathrm{~h})$. Subsequently, the cells were incubated for $4 \mathrm{~h}$ with $20 \mu 15 \mathrm{mg} / \mathrm{ml} \mathrm{MTT}$ solution at $37^{\circ} \mathrm{C}$, and the MTT liquid was aspirated and $150 \mu \mathrm{l}$ DMSO were added to each well. Finally, the plate was shaken for $10 \mathrm{~min}$ and the absorbance was measured at $490 \mathrm{~nm}$ using a microplate reader (Infinite M200; Tecan Group, Ltd.). Cell viability was calculated using the optical density (OD) as follows: Cell viability $(\%)=\left(\mathrm{OD}_{\text {treatment }}-\mathrm{OD}_{\text {blank }}\right) /\left(\mathrm{OD}_{\text {control }}-\mathrm{OD}_{\text {blank }}\right) \times 100 \%$. The half maximal inhibitory concentration (IC50) values were calculated using the Probit regression test in SPSS 22.0 software.

To explore the role of autophagy in the antitumor properties of RSV, pre-treatment with 3-MA (5 mM) for $1 \mathrm{~h}$ was used to inhibit autophagy, and subsequently, MTT assays were used to detect cell viability following co-treatment with RSV $(0,25,50$ or $100 \mu \mathrm{M})$ for $48 \mathrm{~h}$. Similarly, pre-treatment with PFT- $\alpha(40 \mu \mathrm{M})$ for $1 \mathrm{~h}$, a specific p53 inhibitor was used to inhibit p53 and cell viability was then detected.

Cell morphological analysis. The A549 cells (5x105/well) were seeded in 6 -well plates for $24 \mathrm{~h}$, then incubated at $37^{\circ} \mathrm{C}$ with various concentrations of RSV. After $48 \mathrm{~h}$ of treatment, the growth features and shapes of cells were compared using an inverted microscope (magnification, x40 and x100; Eclipse Ts2; Nikon Corporation).

Flow cytometric analysis. The proportion of apoptotic cells were measured using an Annexin V-FITC/PI apoptosis detection kit. Briefly, the A549 cells $\left(5 \times 10^{5} /\right.$ well) were seeded in 6 -well plates overnight and treated with various concentrations of RSV for $48 \mathrm{~h}$ with or without different inhibitors. The cells were collected using EDTA-free trypsin, then washed once with cold PBS and resuspended in a binding buffer (400 $\mu \mathrm{l} /$ well). Following staining with $5 \mu \mathrm{l}$ Annexin V-FITC at room temperature for $15 \mathrm{~min}$ in the dark and $10 \mu \mathrm{PI}$ at $4^{\circ} \mathrm{C}$ for a further $5 \mathrm{~min}$ in the dark, the apoptotic cells were detected using a flow cytometer (FACSCalibur; BD Biosciences) within 30 min. FITC was detected using channel FL1, and PI was detected using channel PI.

(TdT-mediated dUTP nick-end labeling) TUNEL assay. The proportion of apoptotic cells was also determined by TUNEL staining with a one-step TUNEL apoptosis assay kit. Briefly, the control cells and RSV-treated cells were fixed in $4 \%$ paraformaldehyde for $30 \mathrm{~min}$ and washed once with cold PBS. Following permeabilization in $0.3 \%$ Triton X-100 for $5 \mathrm{~min}$ in a room temperature, the cells were washed and incubated in TUNEL detection reagent for $1 \mathrm{~h}$ at $37^{\circ} \mathrm{C}$ in the dark. Subsequently, the cells were washed twice and incubated with DAPI for $3 \mathrm{~min}$ in a room temperature to stain nuclei of total cells (blue color). Finally, the cells were observed under an inverted fluorescence microscope (magnification, x100; Eclipse Ti-S, Nikon Corporation) with blue excitation and UV excitation, respectively. The proportion of TUNEL-positive cells (green color) was assessed from 10 random fields per well.

MDC staining assay. MDC, an eosinophilic fluorescent stain, which selectively labels acidic autophagic vacuoles, is typically used as a specific marker for the detection of autophagy. The A549 cells $\left(5 \times 10^{4} /\right.$ well) were seeded in a 24 -well plate overnight and treated with various concentrations of RSV for $48 \mathrm{~h}$ with or without different inhibitors. Following staining with MDC $(50 \mu \mathrm{M})$ in RPMI-1640 at $37^{\circ} \mathrm{C}$ for $15 \mathrm{~min}$ in the dark, the cells were washed twice with PBS and immediately imaged using an inverted fluorescence microscope (magnification, x100; Eclipse Ti-S; Nikon Corporation) with UV excitation. The mean of the integrated option density was calculated by Image-Pro Plus version 6.0 (Media Cybernetics, Inc.).

Transmission electron microscopy observation. Following treatment with $100 \mu \mathrm{M} \mathrm{RSV}$, or the control (DMSO) at a $0.1 \%$ final concentration for $48 \mathrm{~h}$, the A549 cells were washed 3 times with PBS, fixed in $2.5 \%$ glutaraldehyde at $4{ }^{\circ} \mathrm{C}$ overnight, and rinsed in $0.1 \mathrm{M}$ phosphate buffer for $30 \mathrm{~min}$. The cells were post-fixed in $1 \%$ osmium tetroxide for $1 \mathrm{~h}$ at $4^{\circ} \mathrm{C}$, and washed with the same buffer for a further $30 \mathrm{~min}$. Following gradient dehydration with ethanol, the cells were then embedded in epoxy resin and cut into $0.1 \mu \mathrm{M}$ sections. The ultra-thin sections were stained with uranyl acetate for $10 \mathrm{~min}$ and citric acid for a further $10 \mathrm{~min}$ at room temperature and finally observed using a transmission electronic microscope (magnification, x10,000 and $x 40,000 ;$ H7650, Hitachi, Ltd.).

$R N A$ extraction and reverse transcription-quantitative PCR (RT-qPCR). The A549 cells were seeded in a 6-well plate overnight and treated with various concentrations $(0,25,50$ or $100 \mu \mathrm{M})$ of RSV for $48 \mathrm{~h}$. Total RNA was isolated using TRIzol ${ }^{\circledR}(1 \mathrm{ml} /$ well $)$ according to the manufacturer's protocol. The concentration and quality $\left(\mathrm{A}_{260} / \mathrm{A}_{280}\right.$ ratio $)$ of total RNA was analyzed using Nanodrop One (Thermo, Fisher Scientific, Inc.). 
The extracted RNA was reverse transcribed into cDNA using PrimeScript RT Master mix on a Veriti 96-Well Thermal Cycler (Thermo Fisher Scientific, Inc.). Briefly, 500 ng of RNA, $2 \mu 1$ of $5 X$ PrimeScript RT Master mix, and RNase-free distilled water were mixed to a final volume of $10 \mu 1$ and reverse transcribed with the following temperature protocol: $37^{\circ} \mathrm{C}$ for $15 \mathrm{~min}$, followed by $85^{\circ} \mathrm{C}$ for $5 \mathrm{sec}$. qRCR was then performed using TB Green Premix Ex Taq II on a LightCycler 96 System Real Time PCR machine (Roche Diagnostics). Each sample was run in a $20 \mu \mathrm{l}$ reaction volume, which included $10 \mu \mathrm{l}$ TB Green, $1 \mu 1$ forward primer $(10 \mu \mathrm{M}), 1 \mu \mathrm{l}$ of reverse primer $(10 \mu \mathrm{M}), 1 \mu \mathrm{l} \mathrm{cDNA}$ template, and $7 \mu 1$ RNase-free distilled water. The thermocycling conditions were as follows: $95^{\circ} \mathrm{C}$ for $30 \mathrm{sec}$; followed by 40 cycles of $95^{\circ} \mathrm{C}$ for $5 \mathrm{sec}$ and $60^{\circ} \mathrm{C}$ for $30 \mathrm{sec}$. The specificity was examined by plotting a melt curve and the relative mRNA expression levels were analyzed using the $2^{-\Delta \Delta C q}$ method (35). The primer sequences used were as follows: GAPDH forward, 5'-CAAGGTCATCCATGACAA CTTTG-3' and reverse, 5'-GTCCACCACCCTGTTGCTGT AG-3'. BAX forward, 5'-CGGGTTGTCGCCCTTTTCTA-3' and reverse, 5'-GGAGACAGGGACATCAGTCG-3'. Bcl-2 forward, 5'-CTTTGAGTTCGGTGGGGTCA-3' and reverse, 5'-GGGCCGTACAGTTCCACAAA-3'. Beclin-1 forward, 5'-GAGGTTGAGAAAGGCGAGACA-3' and reverse, 5'-GAG GACACCCAAGCAAGACC-3'. and p62 forward, 5'-GCA CCCCAATGTGATCTGC-3', and reverse, 5'-CGCTACACA AGTCGTAGTCTGG-3'. GAPDH was used as the internal control.

Protein extraction and western blot analysis. Cells were lysed using RIPA lysis buffer (200 $\mu \mathrm{l} /$ well), and centrifuged at $12,000 \mathrm{x}$ g for $5 \mathrm{~min}$ at $4^{\circ} \mathrm{C}$. A BCA protein assay kit was used to measure the concentration of the protein samples.

Equal quantities of protein samples $(20 \mu \mathrm{g})$ were loaded on a 10 or $12 \%$ SDS-gel, and resolved using SDS-PAGE, and transferred to 0.45 or $0.22 \mu \mathrm{m}$ PVDF membranes which were soaked in methanol for $1 \mathrm{~min}$ in advance. The membranes were then blocked with 5\% non-fat dry milk for $1 \mathrm{~h}$ at room temperature, washed 3 times with TBS-Tween (TBST), and incubated with primary antibodies against GAPDH $(1: 10,000$; cat.no. 10494-1-AP), Bax (1:1,000; cat. no. 5023), Bcl-2 (1:1,000; cat. no. 4223), pro-caspase-3 (1:1,000; cat. no. ab32150), cleaved caspase-3 (1:1,000; cat. no. 9661), LC3B (1:1,000; cat. no. 3868), Beclin-1 (1:1,000; cat. no. 3495), p62 (1:1,000; cat. no. 8025), P53 (1:1,000; cat. no. 2527), p-MDM2 (1:1,000; cat. no. 3521), Akt (1:1,000; cat. no. 4691), or p-Akt (1:2,000; cat. no. 4060) overnight at $4^{\circ} \mathrm{C}$. After washing the membranes another 3 times with TBST, membranes were incubated with goat anti-rabbit HRP-conjugated secondary antibody (1:10,000; cat. no. SA00001-2) for $1 \mathrm{~h}$ at room temperature and washed with TBST. The protein brands were visualized using a chemiluminescence imaging system (Gene Gnome XPQ; Syngene) following treatment with immobilon western chemiluminescence HRP substrate for $1 \mathrm{~min}$. Densitometric analysis was performed using ImageJ software version 1.8.0 (National Institutes of Health). GAPDH was used as the loading control.

Statistical analysis. All experimental data are presented as the means \pm standard deviation of 3 independent experiments. Statistical analysis was performed using SPSS version 22.0
(IBM, Corp.) and GraphPad Prism version 5 (GraphPad Software, Inc.). The differences between $>3$ groups were analyzed using a one-way ANOVA with a Dunnett's t-test or Tukey's test. Differences between 2 groups were compared using a Student's t-test. $\mathrm{P}<0.05$ was considered to indicate a statistically significant difference.

\section{Results}

Identification of DEGs. Based on the inclusion and exclusion criteria, only one gene expression profile dataset (GSE9008) retrieved from GEO database was enrolled in the present study to identify the DEGs between the RSV-treated NSCLC samples and the control NSCLC samples (36). Based on the Affymetrix Human Genome U133 Plus 2.0 Array GPL570 platform, the GSE9008 dataset, which was submitted by Whyte et al (36) contained 4 samples, including 1 control NSCLC sample and 3 RSV-treated NSCLC samples.

In total, 1,031 DEGs were identified in the RSV-treated NSCLC samples when compared with the control NSCLC sample with the threshold set as $\mathrm{P}<0.05$ and a $\log \mathrm{FC}>11.21$ as the cut-off criteria (Table SI). Among these DEGs, 680 upregulated genes and 351 downregulated genes were identified, and these are presented with different colors in the volcano plot (Fig. 1A). The top 50 DEGs are shown as a heatmap (Fig. 1B).

Enrichment analysis. The 1,031 DEGs were analyzed using DAVID to identify the enriched GO categories and KEGG pathways. GO analysis included 3 groups, cellular component (CC), biological processes (BP) and molecular function (MF). For CC, DEGs were significantly enriched in the plasma membrane, the integral component of the plasma membrane, the anchored component of the membrane, extracellular space, extracellular region and others. For BP, the DEGs were significantly enriched in the intrinsic apoptotic signaling pathway in response to DNA damage by p53 class mediator, the inflammatory response, innate immune response, cytolysis, peptide catabolic process and others. For MF, the DEGs were significantly enriched in serine-type peptidase activity, calcium ion binding, the regulation of blood pressure, glucose binding, cation channel activity, glucokinase activity and others. Using a threshold of $\mathrm{P}<0.05$, the DEGs were significantly enriched in 78 GO categories (Table SII); of these, the $28 \mathrm{GO}$ categories with a $\mathrm{P}<0.01$ are expressed as a bar chart (Fig. 2A).

Using $\mathrm{P}<0.05$, there were 6 KEGG pathways enriched by DEGs, including P53 signaling pathway, complement and coagulation cascades pathway, butirosin and neomycin biosynthesis pathway, arachidonic acid metabolism pathway, starch and sucrose metabolism pathway, as well as metabolic pathways (Fig. 2B; Table SIII).

RSV induces the death of A549 cells. Although bioinformatics play a main role in predicting DEGs and enriched GO categories and KEGG pathways, the tools and algorithms used in bioinformatics are mostly based on observations of a limited number of known genes. Thus, its accuracy still remains challenge and should be experimentally verified.

To determine the effects of RSV on cell viability, the A549 cells were incubated with RSV at various concentrations $(0,25,50,100$ and $200 \mu \mathrm{M})$ for various periods of time 
A

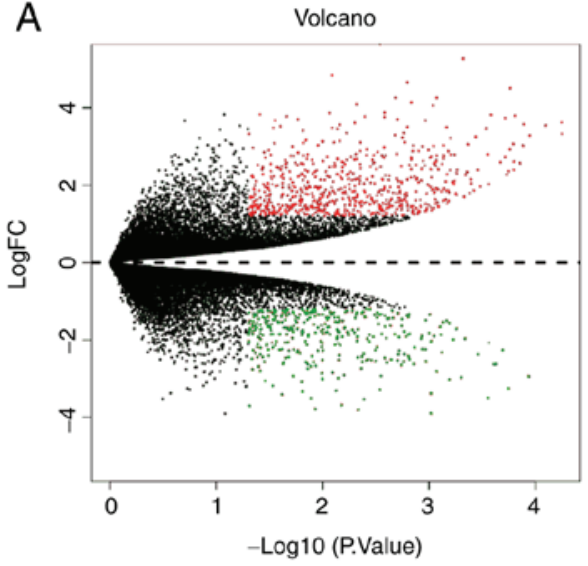

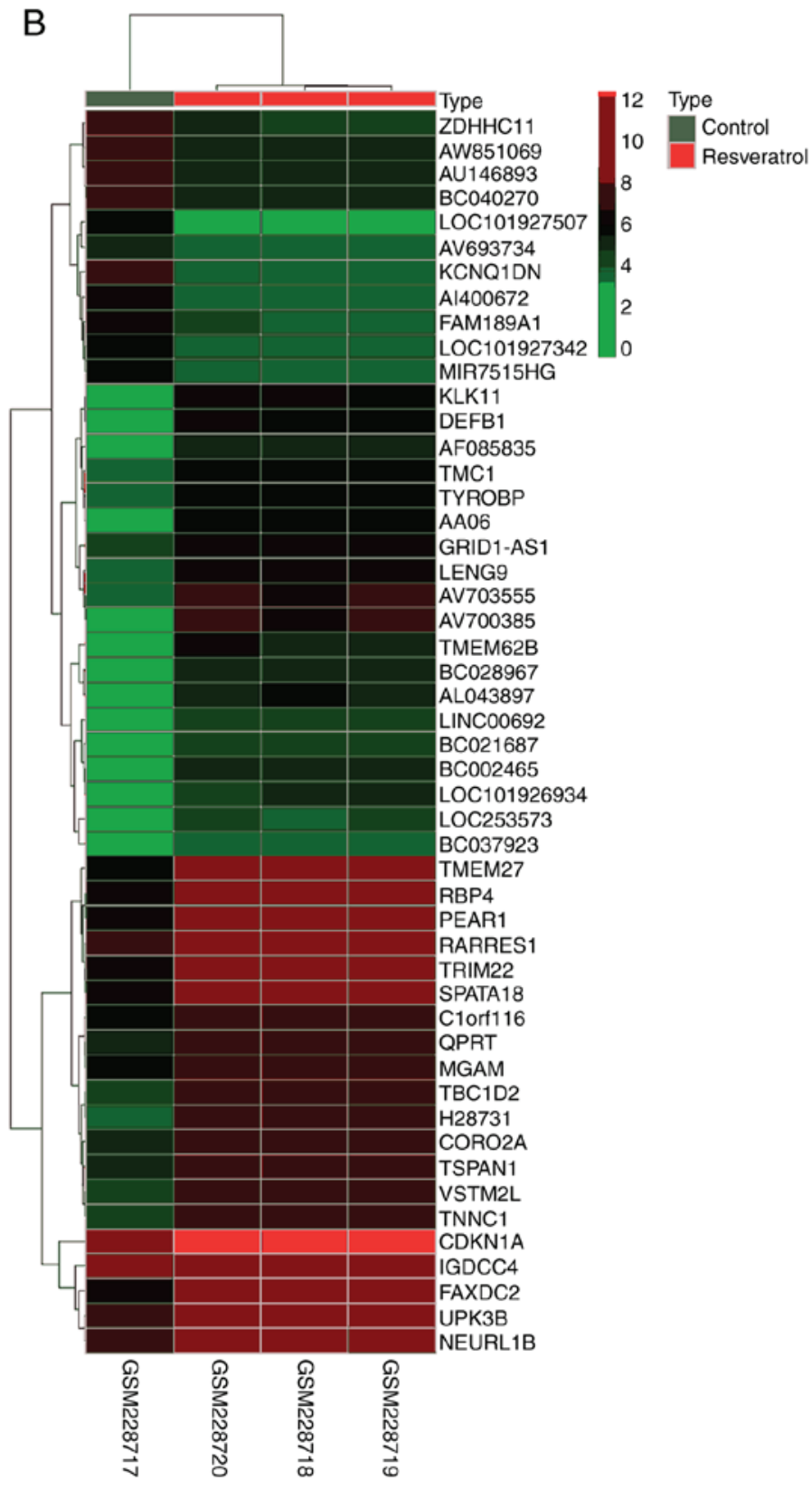

Figure 1. DEGs in the expression profile dataset GSE9008. (A) Volcano plot showing the 1,031 DEGs between A549 cell lines treated with RSV or control for $48 \mathrm{~h}$. Red dots represent downregulated genes and blue dots represent upregulated genes. (B) Heat map showing the 50 DEGs between A549 cells treated with $\mathrm{RSV}$ or control for $48 \mathrm{~h}$. Green represents low expression and red represents high expression. P<0.05. DEG, differentially expressed genes; RSV, resveratrol.

(24, 48 and $72 \mathrm{~h}$ ), and an MTT assay was used to assess cell viability. The results revealed that RSV significantly decreased the viability of the A549 cells in a dose- and time-dependent manner in $(\mathrm{P}<0.01$; Fig. $3 \mathrm{~A})$. The half maximal inhibitory concentration $\left(\mathrm{IC}_{50}\right)$ values of RSV were 91.77 and $71.71 \mu \mathrm{M}$ in the A549 cells treated for 48 and $72 \mathrm{~h}$, respectively. Additionally, the $\mathrm{IC}_{50}$ values were significantly decreased following $48 \mathrm{~h}$ of RSV treatment; thus, $48 \mathrm{~h}$ of treatment was used for subsequent experiments.

To confirm whether RSV inhibits the growth of A549 cells morphologically, the growth features and morphological alterations were detected using an inverted microscope at magnifications of $x 40$ and $x 100$. In the control group, the A549 cells grew well with a typical fusiform shape, cobblestone-like morphology, regular arrangement in a monolayer and clear contours, whereas the growth of RSV-treated cells was gradually attenuated, and abnormal morphological changes and floating dead cells were observed (Fig. 3B). These morphological changes further suggested that RSV induced cell death.

RSV induces the apoptosis of A549 cells. DEGs generated by RSV were enriched in apoptosis according to the results of above-mentioned bioinformatics. To determine whether RSV-induced cell death was associated with apoptosis, flow cytometry, TUNEL assay, RT-qPCR assay and western blot analysis were performed. Following RSV treatment at the indicated concentrations, there was an increase in the number of apoptotic cells based on the flow cytometric analysis with Annexin V-FITC/PI double staining. As shown 


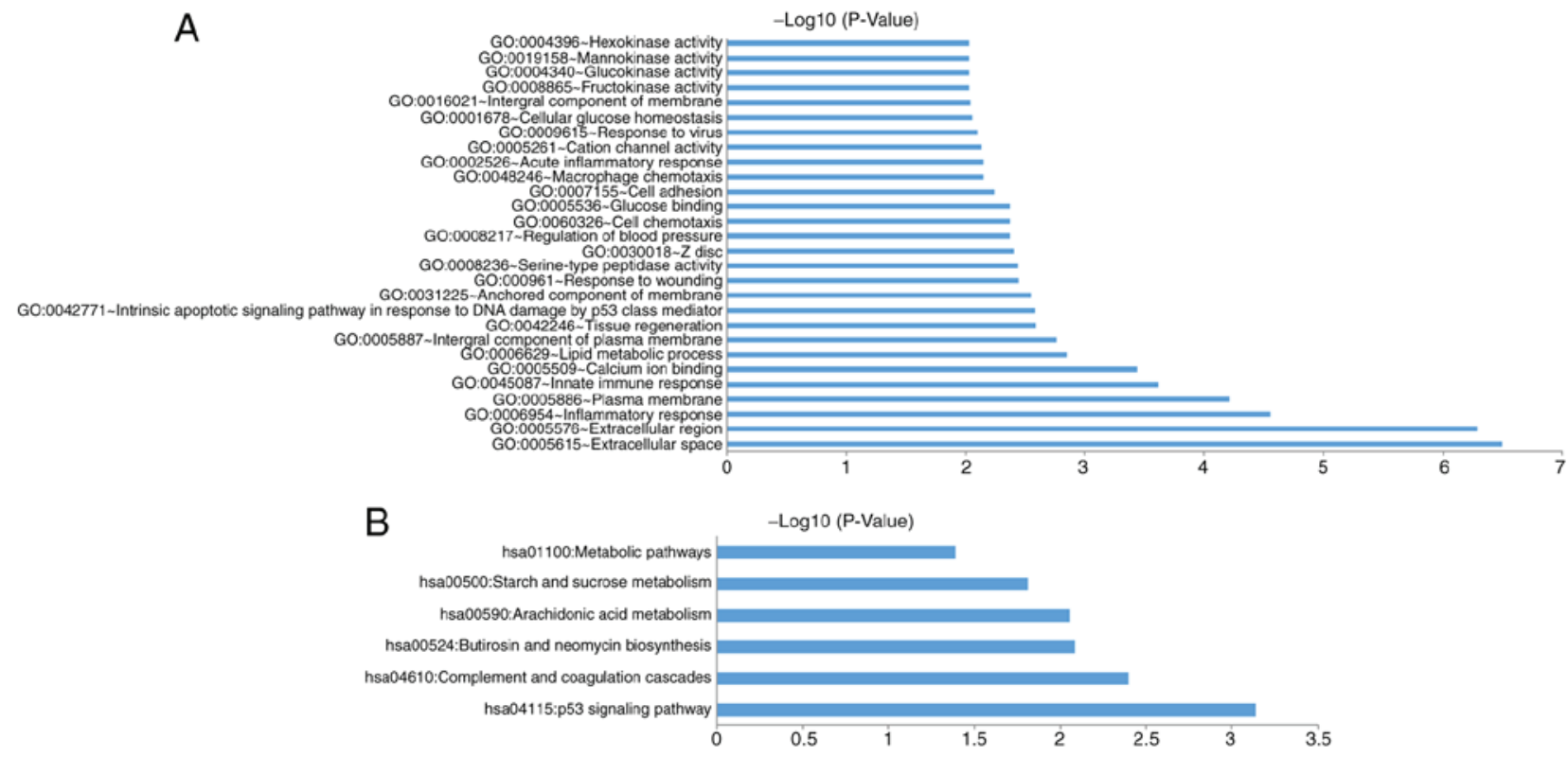

Figure 2. GO and KEGG pathway function annotation of DEGs associated with RSV treatment in A549 cells. (A) DEGs significantly enriched in 28 GO categories. $\mathrm{P}<0.01$. (B) DEGs significantly enriched in 6 KEGG pathways. $\mathrm{P}<0.05$. GO, Gene Ontology; KEGG, Kyoto Encyclopedia of Genes and Genomes; DEG, differentially expressed genes; RSV, resveratrol.

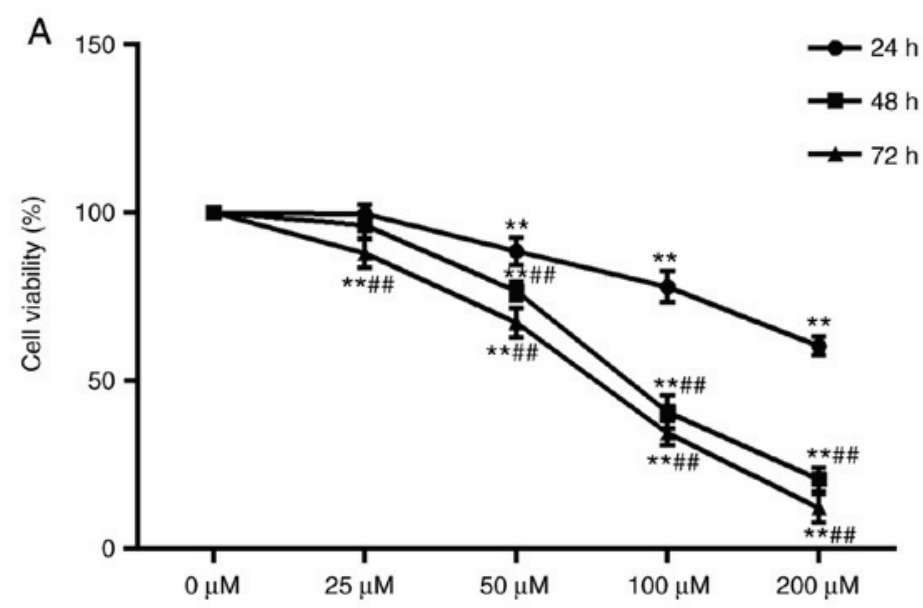

B
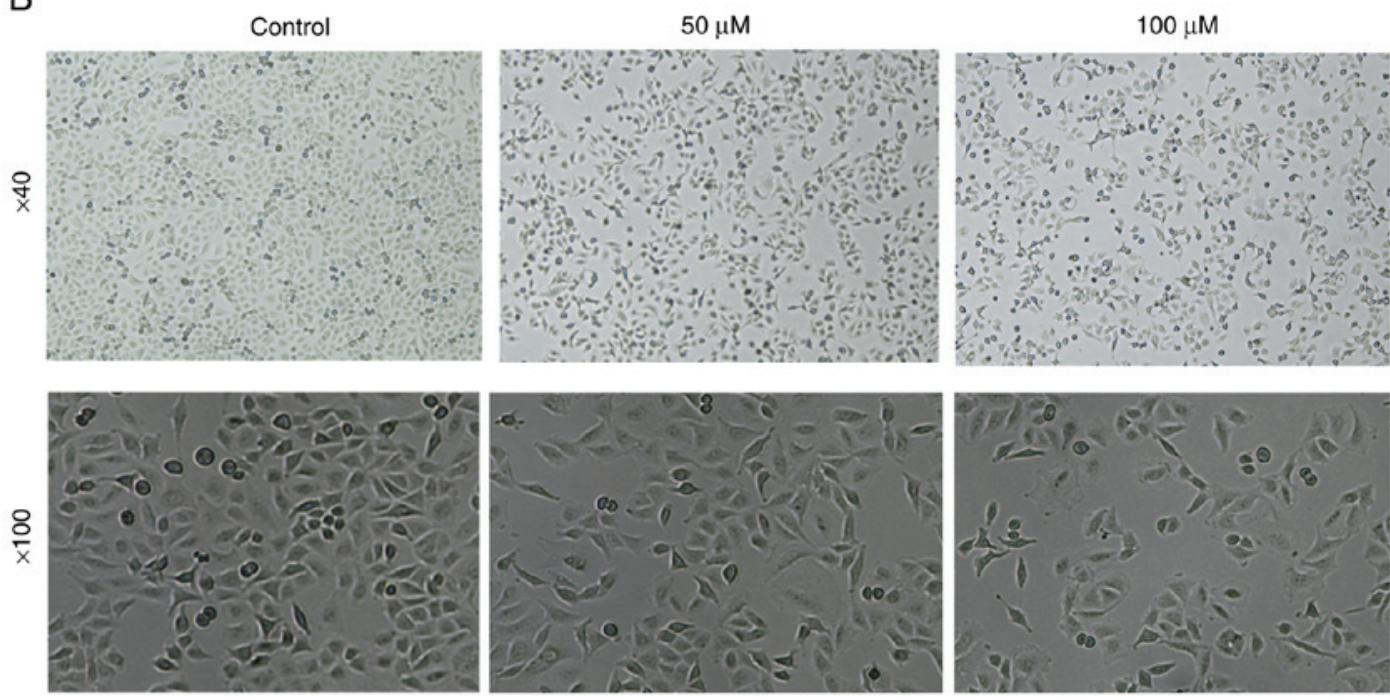

Figure 3. RSV-induced growth inhibition and morphological features of A549 cells. (A) A549 cells were treated with various concentrations of RSV for various periods of time and were assessed by MTT assay. ${ }^{* *} \mathrm{P}<0.01$ vs. $0 \mu \mathrm{M} ;{ }^{\# \prime} \mathrm{P}<0.01 \mathrm{vs}$. $24 \mathrm{~h}$. A one-way ANOVA followed by a Tukey's test was used to compare the data. (B) A549 cells treated with various concentrations of RSV for $48 \mathrm{~h}$ were observed under an inverted microscope. Magnification, $\mathrm{x} 40$ and x100. RSV, resveratrol. 
A
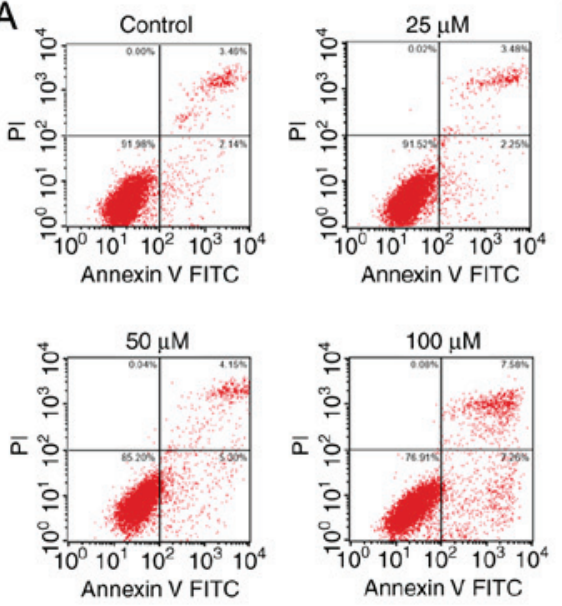

$\star \star$

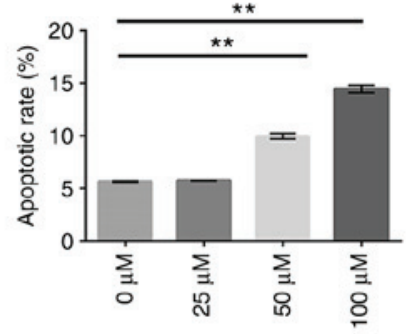

B
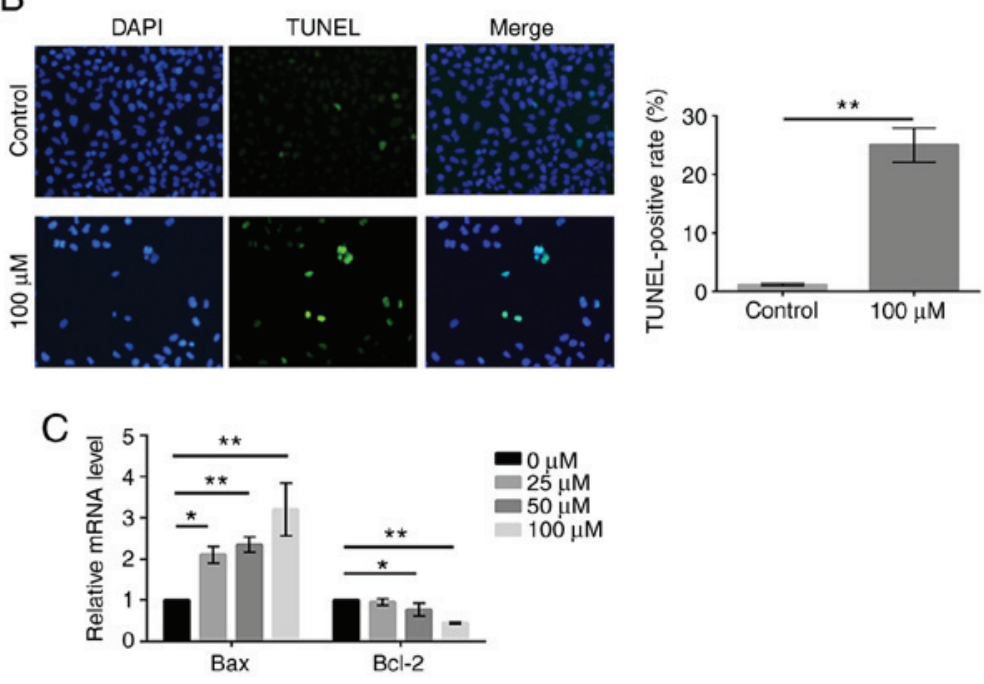

D

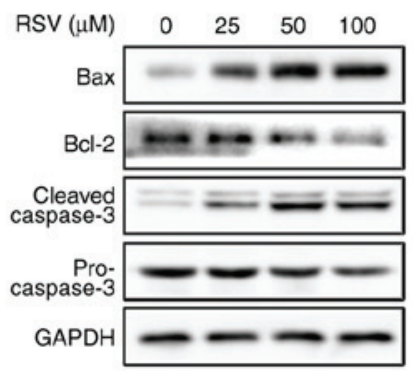

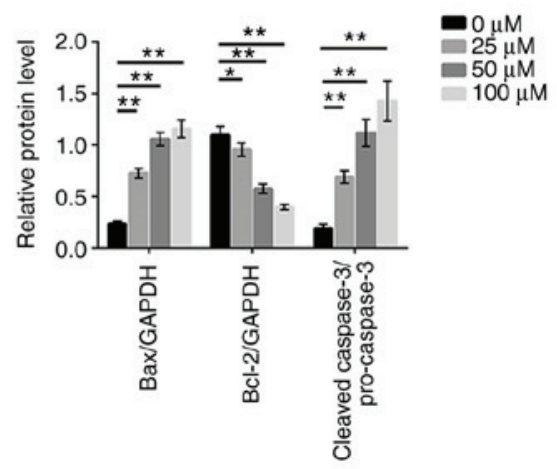

Figure 4. RSV induces the apoptosis of A549 cells. A549 cells were treated with various concentrations of RSV for 48 h and (A) the proportion of apoptotic cells were detected using Annexin V-FITC/PI double staining; (B) the percentage of apoptotic cells was assessed using TUNEL staining; (C) the mRNA expression levels of Bax and Bcl-2 were detected; and (D) the protein expression levels of cleaved caspase-3/pro-caspase-3, Bax and Bcl-2 were detected. The Student's t-test and one-way ANOVA followed by a Dunnett's multiple comparison t-test were used to compare the data. ${ }^{*} \mathrm{P}<0.05,{ }^{* *} \mathrm{P}<0.01 \mathrm{vs} .0 \mu \mathrm{M}$. RSV, resveratrol; FITC, fluorescein isothiocyanate; PI, propidium iodide; TUNEL, TdT-mediated dUTP nick-end labeling.

in Fig. 4A, compared with the control group, the apoptotic rates increased to 9.98 and $14.47 \%$ following treatment with 50 and $100 \mu \mathrm{M}$ RSV, respectively $(\mathrm{P}<0.01)$. Similarly, the rate of TUNEL-positive cells was also significantly higher in the RSV-treated group than in the control group ( $\mathrm{P}<0.01$, Fig. 4B). These results preliminarily suggested that RSV significantly induced apoptosis in A549 cells after $48 \mathrm{~h}$ treatment.

In addition, caspase- 3 activation was measured by detecting the ratio of cleaved caspase-3/pro-caspase- 3 by western blot analysis, and the levels of Bax and $\mathrm{Bcl}-2$ were measured by both RT-qPCR and western blot analysis. Caspase-3 is a critical executioner of apoptosis, and its activation requires the proteolytic processing of its inactive zymogen into activated cleaved caspase-3. As shown in Fig. 4D, the levels of cleaved caspase-3/pro-caspase-3 were significantly increased following RSV treatment for $48 \mathrm{~h}$ in the A549 cells $(\mathrm{P}<0.01)$. Based on the RT-qPCR analysis, the Bax mRNA levels were increased, whereas the Bcl-2 mRNA levels were decreased (Fig. 4C). Additionally, RSV treatment significantly increased the Bax protein expression levels and decreased the Bcl-2 protein expression levels, which followed the same trend with mRNA expression levels (Fig. 4D). These results suggest that RSV plays an important role in regulating the apoptosis of A549 cells.
RSV induces the autophagy of A549 cells. Considering that several autophagy-associated biological functions were enriched in bioinformatics analysis and previous studies on plant polyphenols and autophagy $(37,38)$, the effects of RSV on autophagy were evaluated by MDC staining, transmission electron microscopy, RT-qPCR and western blot analysis. Cells were stained with MDC, and as shown in Fig. 5A, compared with the control group, A549 cells treated with 50 and $100 \mu \mathrm{M}$ $\mathrm{RSV}$ for $48 \mathrm{~h}$ exhibited an increase in the presence of green dot-like structures in the cytoplasm and perinuclear regions, which represent mature autophagic vacuoles. In addition, in the cells treated with $100 \mu \mathrm{M}$ RSV following pre-treatment with 3-MA for $1 \mathrm{~h}$, the proportion of cells exhibiting fluorescence particles was significantly reduced compared with the cells treated with $100 \mu \mathrm{M}$ RSV alone $(\mathrm{P}<0.01$, Fig. 5A).

Taking into account the non-specificity of MDC staining, transmission electron microscopy, which is widely regarded as the gold standard for assessing autophagy, was used to detect the presence of autophagosomes, a hallmark feature of autophagy (39). As shown in Fig. 5B, the untreated A549 cells exhibited a normal cytoplasm, nucleus and organelles without autophagic vacuoles at $48 \mathrm{~h}$. By contrast, numerous double-membraned structures, considered to 


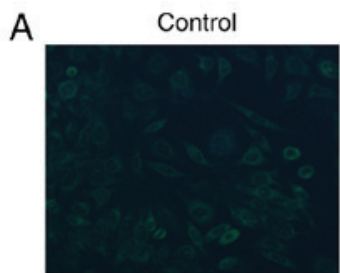

$100 \mu \mathrm{M}$

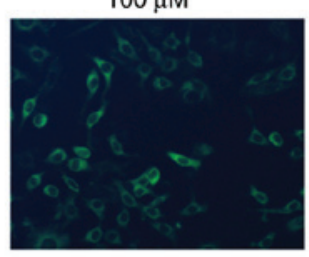

B
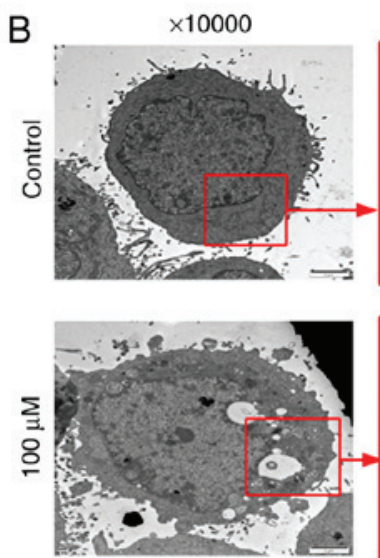

D

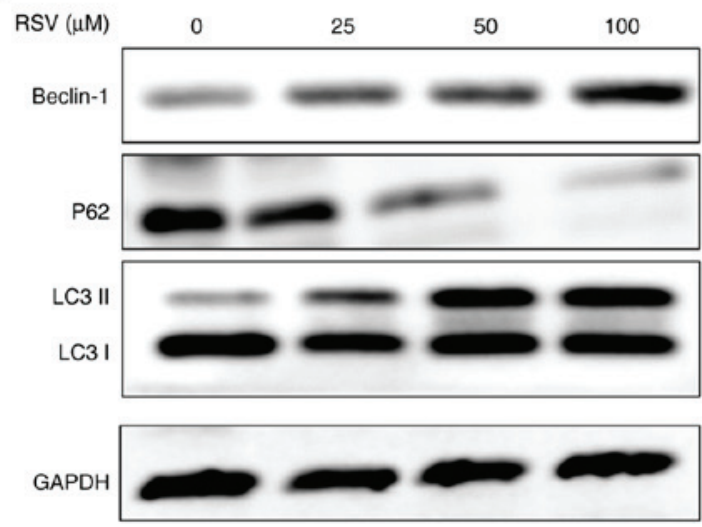

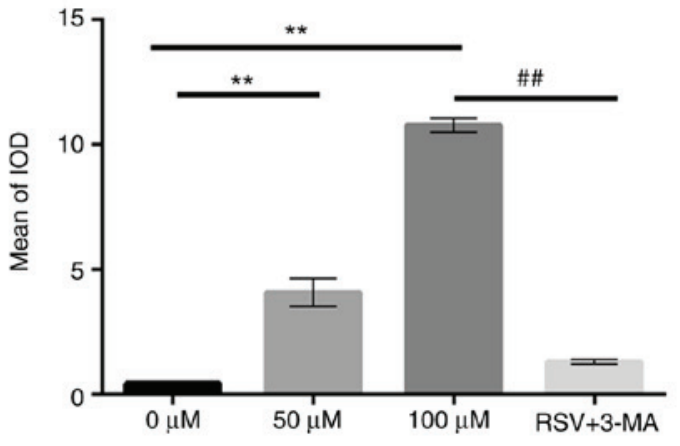
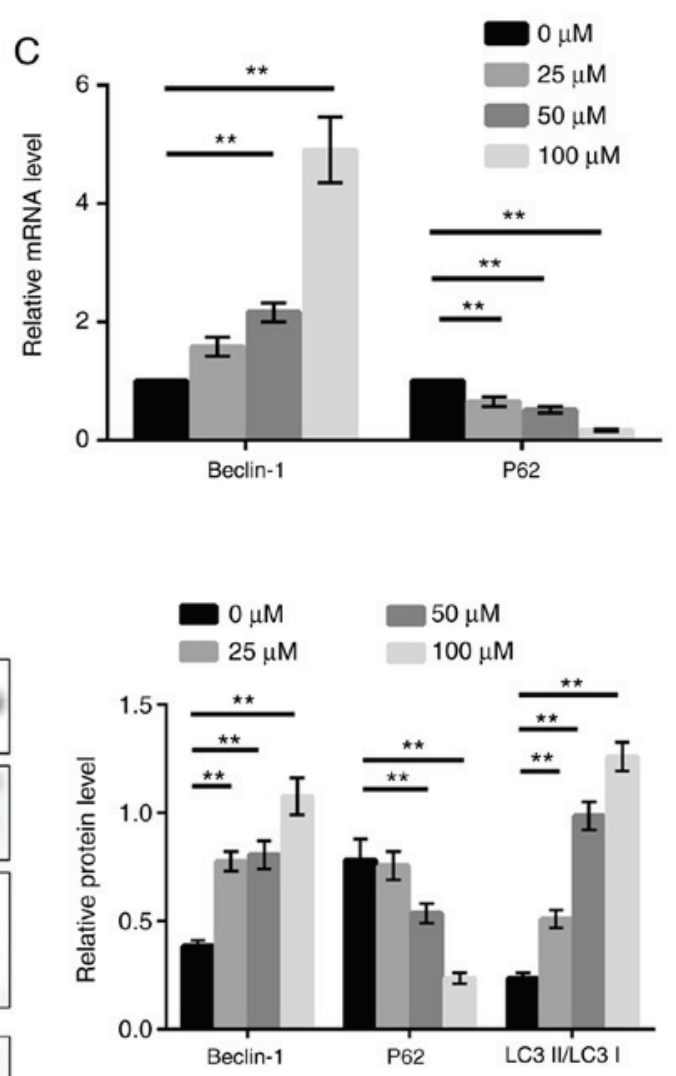

Figure 5. RSV induces autophagy of A549 cells. (A) A549 cells treated with 0,50 or $100 \mu \mathrm{M} \mathrm{RSV}$ for $48 \mathrm{~h}$, or pre-treated with 3-MA (5 mM) for $1 \mathrm{~h}$ followed by $100 \mu \mathrm{M}$ RSV treatment for a further $48 \mathrm{~h}$ were stained with MDC, and observed under an inverted fluorescence microscope. Magnification, x100. Fluorescence particles were quantified and compared using the mean of the IOD. (B) A549 cells were cultured with or without $100 \mu \mathrm{M}$ RSV for $48 \mathrm{~h}$ and observed under a transmission electron microscope. Magnification, $\mathrm{x} 10,000$ and x40,000). White arrows indicate the autophagosomes. (C) A549 cells were treated with various concentrations of RSV for $48 \mathrm{~h}$ and the Beclin-1 and P62 mRNA expression levels were determined. (D) A549 cells were treated with various concentrations of RSV for $48 \mathrm{~h}$ and the LC3-II/LC3-I, Beclin-1 and p62 protein expression levels were detected by western blot analysis. A one-way ANOVA followed by a Dunnett's multiple comparison t-test or Tukey's test was used to compare the data. ${ }^{* *} \mathrm{P}<0.01$ vs. $0 \mu \mathrm{M}$; ${ }^{\# \#} \mathrm{P}<0.01$ vs. $100 \mu \mathrm{M}+3-\mathrm{MA}$. RSV, resveratrol; MDC, monodansylcadaverine; IOD, integrated optical density; 3-MA, 3-methyladenine.

be autophagosomes, were detected in RSV-treated cells after $48 \mathrm{~h}$. Furthermore, certain vacuoles of autophagosomes also contained damaged organelles, such as mitochondrion and endoplasmic reticulum.

To further assess RSV-induced autophagy in A549 cells, LC3 conversion was measured by western blotting, and the protein expression levels of Beclin-1 and P62 were measured using both RT-qPCR and western blotting. During autophagy, LC3-I is converted into LC3-II, which is further recruited to the membranes of autophagosomes (40). As shown in Fig. 5D, the ratio of LC3-II/LC3-I was significantly increased following treatment with RSV for $48 \mathrm{~h}$ in A549 cells $(\mathrm{P}<0.01)$. RT-qPCR analysis revealed that Beclin-1 mRNA expression was increased, whereas the expression of p62 mRNA was decreased in the A549 cells treated with RSV in a dose-dependent manner (Fig. 5C). Correspondingly, there was an increase in Beclin-1 protein expression levels and a decrease in p62 protein expression levels following RSV treatment (Fig. 5D). 


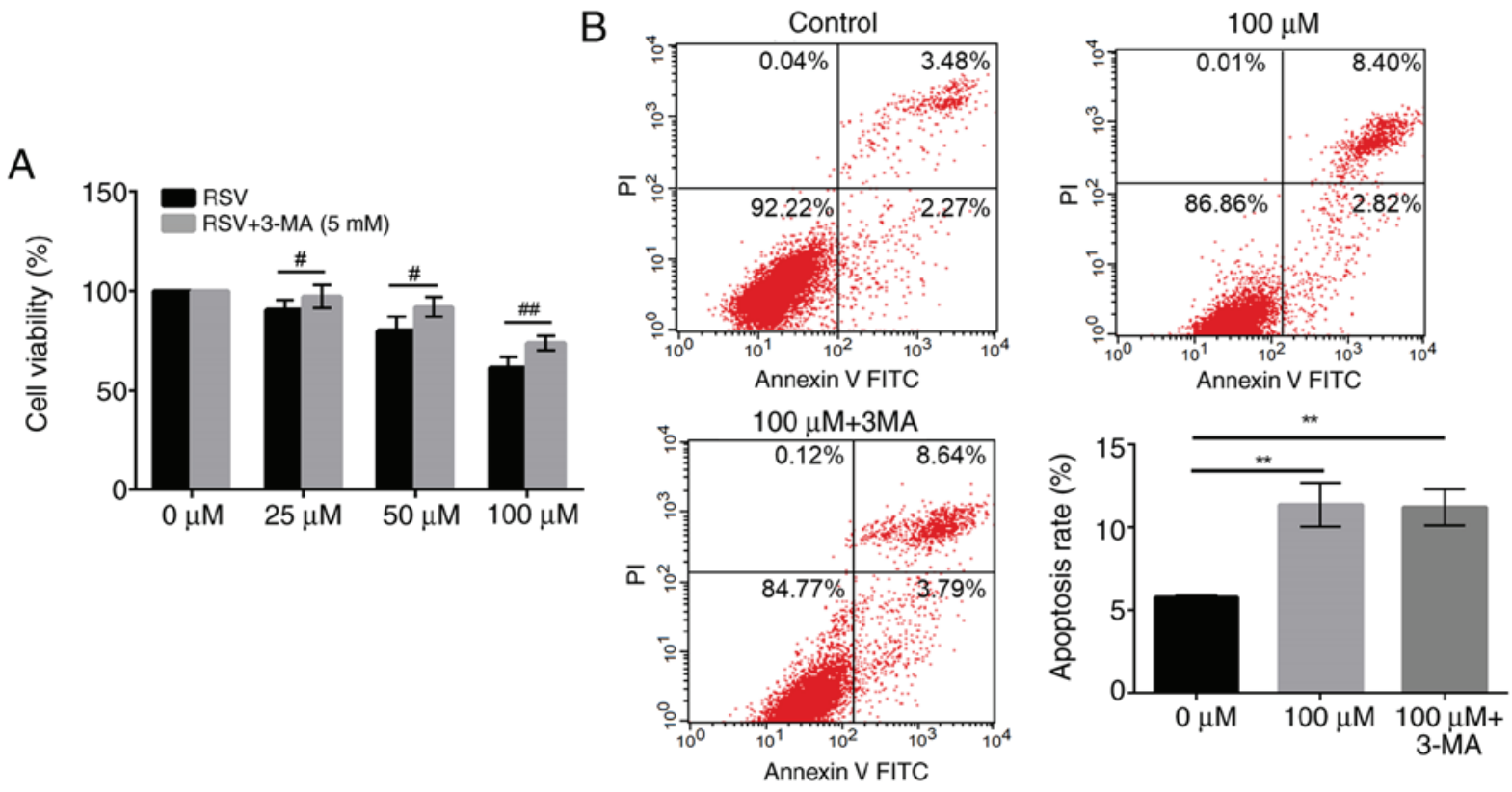

Figure 6. RSV induces the autophagic death of A549 cells. (A) A549 cells were treated with various concentrations of RSV for 48 h with or without 3-MA pretreatment $(5 \mathrm{mM})$, and an MTT assay was performed to examine cell viability. Student's t-test was used to compare the data. ${ }^{\#} \mathrm{P}<0.05$, ${ }^{\#} \mathrm{P}<0.01 \mathrm{vs}$. RSV group. (B) A549 cells were incubated with 0 or $100 \mu \mathrm{M} \mathrm{RSV}$, or $5 \mathrm{mM} 3$-MA followed by $100 \mu \mathrm{M}$ RSV for $48 \mathrm{~h}$, and the proportion of apoptotic cells was detected using Annexin V-FITC/PI double staining. A one-way ANOVA followed by a Tukey's test was used to compare the data. ${ }^{* *} \mathrm{P}<0.01$ vs. $0 \mu \mathrm{M}$. RSV, resveratrol; FITC, fluorescein isothiocyanate; PI, propidium iodide; 3-MA, 3-methyladenine.

These results suggest that RSV plays a crucial role in inducing the autophagy of A549 cells.

RSV induces the autophagic death of A549 cells. Autophagy is associated with both cell survival and cell death. To determine whether autophagy induced by RSV treatment resulted in a decreased cell viability, 3-MA, a widely recognized autophagy inhibitor was used (41). Following pre-treatment with 3-MA, the decrease in cell viability following RSV treatment was significantly reversed. As shown in Fig. 6A, cell viability in the 3-MA-pre-treated group was significantly increased from 90.67 to $97.63 \%$ in the cells treated with $25 \mu \mathrm{M}$ RSV $(\mathrm{P}<0.05)$, from 80.00 to 92.11 in the cells treated with $50 \mu \mathrm{M}$ RSV $(\mathrm{P}<0.01)$, and from 61.56 to $73.67 \%$ in the cells treated with $100 \mu \mathrm{M}$ RSV $(\mathrm{P}<0.01)$, respectively, compared with RSV treatment alone (Fig. 5A). These results suggest that RSV-induced autophagy may be partly responsible for cell death in A549 cells.

To further verify that 3-MA counteracted the inhibitory effects of RSV on the growth of A549 cells due to suppression of autophagy, but not apoptosis, the proportion of apoptotic cells was detected using Annexin V-FITC/PI double staining. As shown in Fig. 6B, although $100 \mu \mathrm{M}$ RSV for $48 \mathrm{~h}$ significantly increased the apoptosis of A549 cells compared with the control group $(\mathrm{P}<0.01)$, there was no notable difference between the groups treated with RSV alone and those pre-treated with 3-MA. Taken together, these results further suggest that RSV induced cell death through autophagy in A549 cells.

RSV modulates the apoptosis and autophagic death of A549 cells via a p53-dependent pathway. Given the results of KEGG enrichment and the critical role of the p53 pathway in controlling cell proliferation, apoptosis and transcription, whether the effect of RSV on A549 cells was associated with P53 pathway was assessed. Western blot analysis was performed to detect the expression of representative signal proteins in the p53 signaling pathway, including p53, MDM2 and Akt. As shown in Fig. 7A, p53 expression was increased in a dose-dependent manner in the RSV-treated cells. Furthermore, the phosphorylation of MDM2 at Ser ${ }^{166}$, which results in the degradation of p53 by ubiquitylation, was inhibited with RSV treatment in the A549 cells, and its upstream regulator, phosphorylation of Akt at $\mathrm{Ser}^{473}$, was also decreased $(\mathrm{P}<0.01)$. These data suggest that RSV induced the activation of the p53 signaling pathway in A549 cells.

To further examine whether the p53 pathway is involved in the RSV-induced apoptosis and autophagy of A549 cells, the effect of PFT- $\alpha$, a specific inhibitor of p53, was assessed on apoptosis- and autophagy-related proteins. As shown in Fig. 7B, pre-treatment with PFT- $\alpha$ attenuated expression of the pro-apoptotic molecule, Bax, and increased the expression of the anti-apoptotic molecule, Bcl-2, compared with the group treated with RSV alone $(\mathrm{P}<0.05)$. Similarly, the expression of the specific autophagic protein, Beclin-1, was decreased and the expression of p62 was increased in the A549 cells pre-treated with PFT- $\alpha(\mathrm{P}<0.05)$. These results demonstrated that the effects of RSV on apoptosis and autophagy were partly reversed by PFT- $\alpha$, suggesting that RSV modulated the apoptosis and autophagy of A549 cells via the p53 pathway.

To determine whether the cytotoxic effects of RSV on the induction of apoptosis and autophagy were associated with the p53 pathway, PFT- $\alpha$ was used in MTT assay, flow cytometry assay and MDC staining assay. As shown in Fig. 7C-E, the results revealed that PFT- $\alpha$ inhibited the antitumor, apoptotic and autophagic effects induced by RSV in 

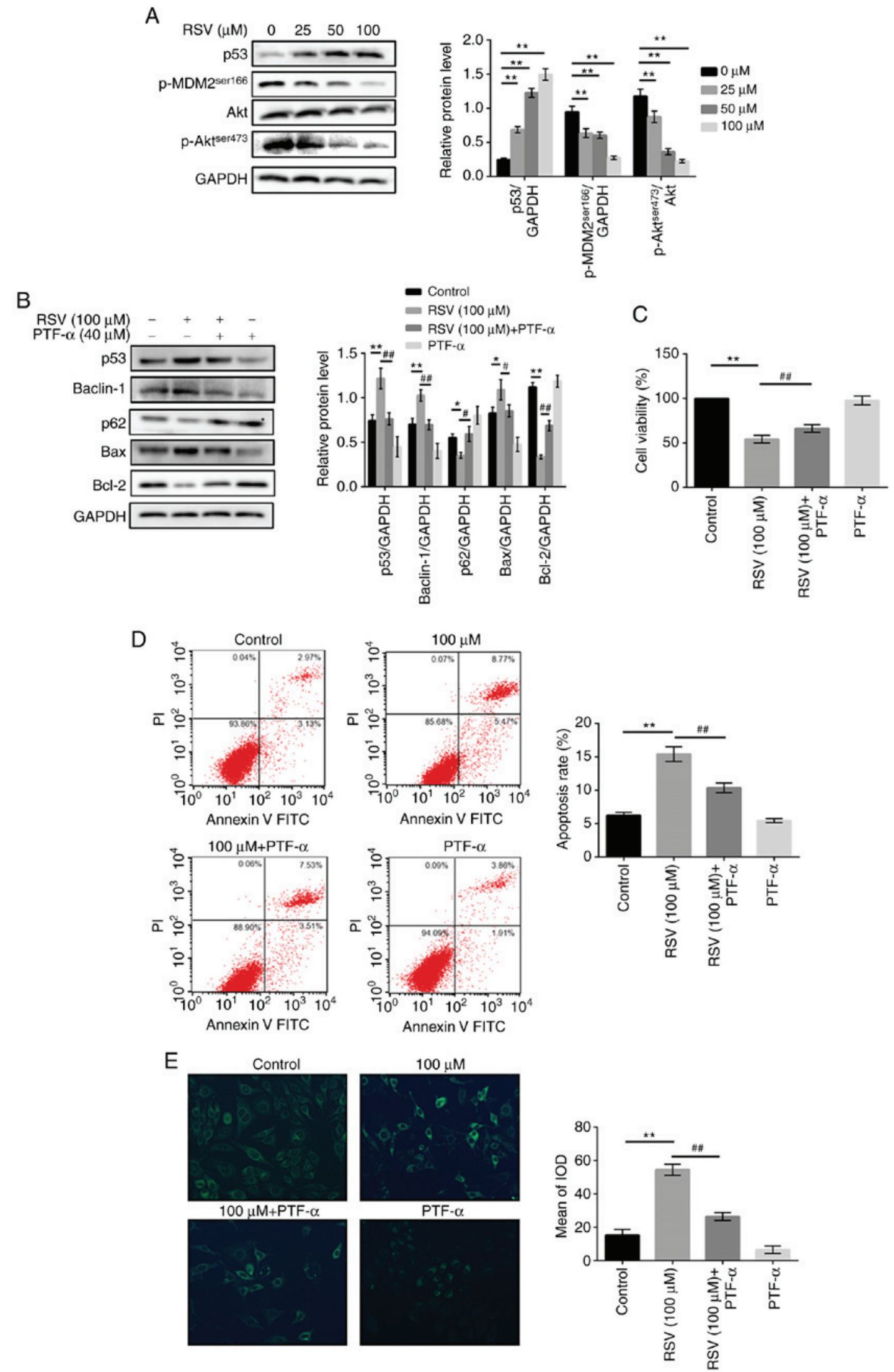

Figure 7. RSV modulates the apoptosis and autophagic death of A549 cells in a p53-dependent manner. (A) A549 cells were treated with various concentrations of RSV for $48 \mathrm{~h}$ and the protein expression levels of p53, p-MDM2 and p-Akt/Akt protein were detected by western blot analysis. **P $<0.01 \mathrm{vs} .0 \mu \mathrm{M}$. (B) A549 cells were incubated with 0 or $100 \mu \mathrm{M}$ RSV, or $40 \mu \mathrm{M}$ PFT- $\alpha$ followed by $100 \mu \mathrm{M} \mathrm{RSV}$ for $48 \mathrm{~h}$, and the expression of Bax, Bcl-2, Beclin-1 and p62 protein expression levels were detected by western blot analysis. (C) Viability of A549 cells treated with $0 \mu \mathrm{M}$ RSV, $40 \mu \mathrm{M}$ PFT- $\alpha, 100 \mu \mathrm{M}$ RSV with or without $40 \mu \mathrm{M}$ PFT- $\alpha$ was detected by MTT assay. (D) The apoptosis of A549 cells treated with $0 \mu \mathrm{M} \mathrm{RSV,} 40 \mu \mathrm{M}$ PFT- $\alpha, 100 \mu \mathrm{M}$ RSV with or without $40 \mu \mathrm{M}$ PFT- $\alpha$ were detected using Annexin V-FITC/PI double staining. (E) The autophagy of A549 cells treated with $0 \mu \mathrm{M} \mathrm{RSV}, 40 \mu \mathrm{M}$ PFT- $\alpha, 100 \mu \mathrm{M}$ RSV with or without $40 \mu \mathrm{M}$ PFT- $\alpha$ were detected using MDC staining. ${ }^{*} \mathrm{P}<0.05,{ }^{* *} \mathrm{P}<0.01$ vs. Control; ${ }^{\#} \mathrm{P}<0.05,{ }^{\# \#} \mathrm{P}<0.01$ vs. RSV group. A one-way ANOVA followed by a Dunnett's multiple comparison t-test or Tukey's test was used to compare the data. RSV, resveratrol; p-, phospho-; PFT- $\alpha$, pifithrin- $\alpha$. 
the A549 cells, compared with RSV treatment alone $(\mathrm{P}<0.01)$, further indicating that RSV exerted its antitumor effects by inducing the apoptosis and autophagic death of A549 cells via p53-dependent signaling.

\section{Discussion}

In recent years, natural polyphenol compounds have attracted widespread attention for the treatment of cancers, including curcumin, RSV, tea polyphenol and phloretin. In previous studies by the authors, the antitumor properties of curcumin in NSCLC were demonstrated $(37,38)$. Thus RSV, another major flavonoid, was examined to determine whether it exhibited antitumor properties, characteristic of the other natural polyphenols, and additionally the underlying mechanisms of its actions were determined in NSCLC. RSV reduced growth of A549 cells, an effect which has been previously demonstrated with other types of cancer cell lines $(9,21)$. However, the specific mechanisms of RSV have been contested.

Based on a microarray dataset (accession no. GSE9008) obtained from GEO database, 1,031 DEGs were identified in the present study, including 680 genes upregulated and 351 genes downregulated following RSV treatment. Based on these DEGs, GO biological function enrichment and KEGG pathway enrichment were performed. The 28 most strongly enriched GO categories $(\mathrm{P}<0.01)$ were extracted among which, apoptotic process, a well-known cytotoxic mechanism, was enriched by CDKN1A, NUPR1, CDIP1, PYCARD, IFI16 and PMAIP1, suggesting that apoptosis may be involved in the cytotoxic effects of RSV in A549 cells. These results are contrary to those of a previous study, which demonstrated that RSV did not have a notable effect on apoptosis (42), whereas other studies have reported that RSV reduced the viability of NSCLC cells through increasing apoptosis, consistent with the predicted results obtained by bioinformatics in the present study $(43,44)$. In the present study, in order to determine whether RSV-induced apoptosis occurred in NSCLC A549 cells, a series of in vitro experiments were performed. Flow cytometry with Annexin V-FITC/PI assay, which is widely used in the detection of apoptotic cells, was first performed in the present study. However, there is some controversy over the FACS histograms. In the majority of studies, the upper left quadrant of the histograms represents necrotic cells (45-47), while in other instances the upper right quadrant refers to late apoptotic and necrotic cells $(48,49)$. Overall, the right panels, including the lower right quadrant and upper right quadrant are recognized as the apoptotic cells. Due to this controversial point, TUNEL assay, as well as RT-qPCR and western blot analysis were also used to detect apoptosis. This part of the study demonstrated that RSV induced the apoptosis of A549 cells, based on the integrated bioinformatics and in vitro experiments. Furthermore, through comprehensive analysis of cell viability and apoptotic rate, the potential involvement of other mechanisms of cell death was considered.

In recent years, autophagy, a catabolic process for degradation of long-lived proteins and organelles, has attracted increasing attention in cancer research (50). In this process, cytosolic components, sequestered by double-membrane vesicles termed autophagosomes, are subsequently transported to lysosomes for degradation (51). The double membrane of autophagosomes originate from multiple membrane sources. Ravikumar et al (52) found that the plasma membrane contributed to autophagosome formation, and this is of particular importance during periods of autophagy. Peptide catabolic process, proteolysis, and plasma membrane which all contribute to the process of autophagy, were significantly enriched following RSV treatment in the present study $(\mathrm{P}<0.05)$. Considering the predicted results of bioinformatics analysis and the possibility of plant polyphenols to initiate autophagy (21,37), it was hypothesized that autophagy may also be stimulated in RSV-treated A549 cells. Thus, whether RSV induced autophagy in vitro was determined. Evidence for RSV-induced autophagy in the present study included the enhancement of green fluorescence, the accumulation of autophagic vacuoles, as well as in the expression of autophagy-associated molecules, confirming the occurrence of autophagy following treatment of the A549 cells with RSV. Previous studies have demonstrated that RSV initiates autophagy in various other types of cancer cells. For example, Puissant and Auberger (53) found that RSV induced autophagy in chronic myelogenous leukemia cells through both AMPK activation and JNK-mediated p62/SQSTM1 expression. There were some studies showing similar results in NSCLC cells $(19,20,42)$, where RSV induced autophagy; however, the exact role of RSV-induced autophagy in NSCLC cells requires further study.

Studies exploring autophagy in different cell types or under different interventions have reported conflicting results. Wang et al (54) verified that RSV promoted protective autophagy via a ceramide/Akt/mTOR pathway in melanoma B16 cells. Conversely, autophagic cell death initiated by RSV was also observed in chronic myelogenous leukemia cells (55). Of interest, both the autophagic cell survival and autophagic cell death induced by RSV has been reported in NSCLC cells $(19,20)$. Therefore, the function of autophagy as a cell death or cell survival mechanism in RSV-treated A549 cells was further explored in the present study using 3-MA, an inhibitor of autophagy. The results revealed that the inhibition of autophagy enhanced cell viability at different concentrations of RSV; however, thus far, it could not be concluded that RSV-induced autophagy resulted in the death of A549 cells. An important point which is commonly neglected in numerous studies, is that 3-MA may also have an impact on RSV-induced apoptosis in A549 cells. Some studies have demonstrated that 3-MA pre-treatment led to a marked decrease in apoptosis $(56,57)$, while in other cases 3 -MA led to an increase in apoptosis $(58,59)$. Additionally, certain studies have demonstrated that 3-MA does not cause an obvious change in the apoptotic cell population in a certain range of time and concentration $(60,61)$. In the present study, no significant effect was observed with 3-MA pre-treatment $(5 \mathrm{mM})$ on RSV-induced apoptosis. Thus, the present results elucidated that RSV-induced autophagy was not cytoprotective, but instead resulted in the death of A549 cells.

Thus far, all the above-mentioned results have suggested that RSV initiated autophagy and apoptosis, collectively triggering cell death; however, which process is dominant or mainly responsible for cell death remains unclear. There are two major obstacles to the elucidation of this issue. Firstly, although both processes are important types of PCD, the 
former is a cell-intrinsic suicide process characterized by chromatin condensation, caspase cascade activation and DNA fragmentation, while the latter is a catabolic process involving the degradation of unwanted macromolecules and organelles mediated by lysosomes (13). Considering that different assays are employed by the two different mechanisms, it is difficult to determine which one is dominant for cell death without a quantitative and comparable assay which can be used in apoptosis and autophagy simultaneously. Furthermore, the interplay between apoptosis and autophagy is complex and highly dependent on the cellular context and different treatments. Under certain circumstances, autophagy inhibits apoptosis or the activation of apoptosis is coupled to the suppression of autophagy $(59,62)$, whereas in other instances, it acts synergistically with apoptosis and is even considered an upstream event of apoptosis $(57,63)$. It also has been found that licochalcone A-induced autophagy is neither pro-nor anti-apoptotic (64). Thus, it is difficult to determine which one might be dominant due to the complex interactions between them. Liu et al (65) attempted to determine whether apoptosis or autophagy was the primary cause of cell death with autophagy inhibitor and pan-caspase inhibitor, but failed to consider the effect of autophagy inhibitor on apoptosis and apoptosis inhibitor on autophagy. In this regard, it is pivotal to clarify the crosstalk between apoptosis and autophagy and then determine the dominant one for cell death in future studies.

Previous studies have demonstrated that autophagy and apoptosis can be stimulated by common upstream signals, including the p53 signaling pathway (24). It has been shown that once MDM2 is phosphorylated by p-Akt, p-MDM2 translocates to the nucleus and promotes ubiquitination, as well as degradation of p53 in the form of p-MDM2-P53, consequently hindering p53-dependent apoptosis (66). However, to the best of our knowledge, there are no studies available to date on the association between Akt-MDM2-p53 signaling and RSV-induced apoptosis and autophagy. The predicted results of bioinformatics in the present study revealed that the p53 signaling pathway was ranked first in the KEGG pathway enrichment list, suggesting that RSV may regulate the p53 pathway in A549 cells. The in vitro experiments revealed that there was an increase in p53 protein expression levels, as well as a decrease in the expression of the molecules, $\mathrm{p}-\mathrm{Akt}$ and $\mathrm{p}-\mathrm{MDM} 2$, indicating that RSV regulated the $\mathrm{p} 53$ pathway in A549 cells. Similar to the present study, previous studies have also found that RSV results in p53 accumulation in NSCLC cells $(67,68)$. Thus, it can be concluded that RSV induced apoptosis and autophagy, and increased p53 expression. Based on these conclusions, it was hypothesized that RSV may induce apoptosis and autophagy via p53-mediated signaling. Using PFT- $\alpha$, a p53 inhibitor, there was a restoration of RSV-induced apoptosis, autophagy and cytotoxicity, indicating that RSV exerted its anti-tumor effects in A549 cells by inducing apoptosis and autophagic cell death via the p53 signaling pathway. To the best of our knowledge, there is no literature available to date regarding the involvement of the p53 pathway in simultaneously regulating the apoptosis and autophagy of RSV-treated A549 cells.

In conclusion, using bioinformatics and in vitro experiments, the present study demonstrated that RSV contributed to tumor suppression by inducing apoptosis and apoptotic cell death via p53-dependent mediated signaling. Therefore, RSV, which can trigger dual cell death mechanisms, may be a viable option for the treatment of NSCLC, providing a rationale for further clinical development. However, the present study has several limitations. Firstly, only one cell line was used which contained wild-type p53. Thus, the RSV-related regulatory mechanism in p53 mutant cell lines remain ambiguous and require further investigation. Secondly, the association between apoptosis and autophagy in the context of RSV-induced cytotoxicity requires further investigation. Thirdly, all the experiments in the present study were performed in vitro. Thus, animal experiments and prospective clinical trials are required to determine whether RSV is a useful and safe anticancer agent.

\section{Acknowledgements}

Not applicable.

\section{Funding}

This study was supported by grants from the Natural Science Basic Research Program of Shaanxi (grant no. 2019JZ-43) and the Fundamental Research Funds for the Central Universities of China (grant no. sxzy022019087).

\section{Availability of data and materials}

The datasets used and/or analyzed during the present study are available from the corresponding author on reasonable request.

\section{Authors' contributions}

YFa, YYu, YC and JL were involved in the conception and design of the study. YYa, and XZ conducted in bioinformatics analysis. YFa, JL, YL and YJ performed the experiments. $\mathrm{LZ}$ and $\mathrm{YFe}$ analyzed and interpreted the data. YFa and YYa drafted the manuscript. YYu and YC supervised the study and revised the manuscript. All authors read and approved the final manuscript.

\section{Ethics approval and consent to participate}

Not applicable.

\section{Patient consent for publication}

Not applicable.

\section{Competing interests}

The authors declare that they have no competing interests.

\section{References}

1. Siegel RL, Miller KD and Jemal A: Cancer statistics, 2018. CA Cancer J Clin 68: 7-30, 2018.

2. Herbst RS, Morgensztern D and Boshoff C: The biology and management of non-small cell lung cancer. Nature 553: 446-454, 2018. 
3. Allemani C, Matsuda T, Di Carlo V, Harewood R, Matz M, Nikšić M, Bonaventure A, Valkov M, Johnson CJ, Estève $\mathrm{J}$, et al: Global surveillance of trends in cancer survival 2000-14 (CONCORD-3): Analysis of individual records for 37513025 patients diagnosed with one of 18 cancers from 322 population-based registries in 71 countries. Lancet 391: 1023-1075, 2018

4. Sharifi-Rad J, Ozleyen A, Boyunegmez TT, Tumer T, Oluwaseun Adetunji C, El Omari N, Balahbib A, Taheri Y, Bouyahya A, Martorell M, et al: Natural products and synthetic analogs as a source of antitumor drugs. Biomolecules 9, 679, 2019.

5. Qian YY, Zhang H, Hou Y, Yuan L, Li GQ, Guo SY, Hisamits T and Liu YQ: Celastrus orbiculatus extract inhibits tumor angiogenesis by targeting vascular endothelial growth factor signaling pathway and shows potent antitumor activity in hepatocarcinomas in vitro and in vivo. Chin J Integr Med 18: 752-760, 2012.

6. Zhou GB, Kang H, Wang L, Gao L, Liu P, Xie J, Zhang FX, Weng XQ, Shen ZX, Chen J, et al: Oridonin, a diterpenoid extracted from medicinal herbs, targets AML1-ETO fusion protein and shows potent antitumor activity with low adverse effects on $\mathrm{t}(8 ; 21)$ leukemia in vitro and in vivo. Blood 109 3441-3450, 2007.

7. Jang M, Cai L, Udeani GO, Slowing KV, Thomas CF, Beecher CW, Fong HH, Farnsworth NR, Kinghorn AD, Mehta RG, et al: Cancer chemopreventive activity of resveratrol, a natural product derived from grapes. Science 275: 218-220, 1997.

8. Hu YQ, Wang J and Wu JH: Administration of resveratrol enhances cell-cycle arrest followed by apoptosis in DMBA-induced skin carcinogenesis in male Wistar rats. Eur Rev Med Pharmacol Sci 20: 2935-2946, 2016.

9. Sun L, Chen B, Jiang R, Li J and Wang B: Resveratrol inhibits lung cancer growth by suppressing M2-like polarization of tumor associated macrophages. Cell Immunol 311: 86-93, 2017.

10. Hu C, Liu Y, Teng M, Jiao K, Zhen J, Wu M and Li Z: Resveratrol inhibits the proliferation of estrogen receptor-positive breast cancer cells by suppressing EZH2 through the modulation of ERK1/2 signaling. Cell Biol Toxicol 35: 445-456, 2019.

11. El-Readi MZ, Eid S, Abdelghany AA, Al-Amoudi HS, Efferth T and Wink M: Resveratrol mediated cancer cell apoptosis, and modulation of multidrug resistance proteins and metabolic enzymes. Phytomedicine 55: 269-281, 2019.

12. Pistritto G, Trisciuoglio D, Ceci C, Garufi A and D'Orazi G Apoptosis as anticancer mechanism: Function and dysfunction of its modulators and targeted therapeutic strategies. Aging (Albany NY) 8: 603-619, 2016.

13. Liu G, Pei F, Yang F, Li L, Amin AD, Liu S, Buchan JR and Cho WC: Role of autophagy and apoptosis in non-small-cell lung cancer. Int J Mol Sci 18: 367, 2017.

14. Yen CM, Tsai CW, Chang WS, Yang YC, Hung YW, Lee HT, Shen CC, Sheu ML, Wang JY, Gong CL, et al: Novel combination of arsenic trioxide (As2O3) plus resveratrol in inducing programmed cell death of human Neuroblastoma SK-N-SH cells Cancer Genomics Proteomics 15: 453-460, 2018

15. Zhang W, Wang X and Chen T: Resveratrol induces apoptosis via a Bak-mediated intrinsic pathway in human lung adenocarcinoma cells. Cell Signal 24: 1037-1046, 2012.

16. Liu Y, Tong L, Luo Y, Li X, Chen G and Wang Y: Resveratrol inhibits the proliferation and induces the apoptosis in ovarian cancer cells via inhibiting glycolysis and targeting AMPK/mTOR signaling pathway. J Cell Biochem 119 6162-6172, 2018

17. Park D, Jeong H, Lee MN, Koh A, Kwon O, Yang YR, Noh J, Suh PG, Park H and Ryu SH: Resveratrol induces autophagy by directly inhibiting mTOR through ATP competition. Sci Rep 6 : 21772, 2016

18. Chang CH, Lee CY, Lu CC, Tsai FJ, Hsu YM, Tsao JW, Juan YN, Chiu HY, Yang JS and Wang CC: Resveratrol-induced autophagy and apoptosis in cisplatin-resistant human oral cancer CAR cells: A key role of AMPK and Akt/mTOR signaling. Int J Oncol 50: 873-882, 2017.

19. Wang J, Li J, Cao N, Li Z, Han J and Li L: Resveratrol, an activator of SIRT1, induces protective autophagy in non-small-cel lung cancer via inhibiting Akt/mTOR and activating p38-MAPK. Onco Targets Ther 11: 7777-7786, 2018.

20. Dasari SK, Bialik S, Levin-Zaidman S, Levin-Salomon V, Merrill AH Jr, Futerman AH and Kimchi A: Signalome-wide RNAi screen identifies GBA1 as a positive mediator of autophagic cell death. Cell Death Differ 24: 1288-1302, 2017.
21. Zhang B, Yin X and Sui S: Resveratrol inhibited the progression of human hepatocellular carcinoma by inducing autophagy via regulating p53 and the phosphoinositide 3 kinase/protein kinase B pathway. Oncol Rep 40: 2758-2765, 2018.

22. Lin YT, Wang HC, Hsu YC, Cho CL, Yang MY and Chien CY Capsaicin induces autophagy and apoptosis in human nasopharyngeal carcinoma cells by downregulating the PI3K/AKT/mTOR pathway. Int J Mol Sci 18: 1343, 2017.

23. Wen Z, Zhang J, Tang P, Tu N, Wang K and Wu G: Overexpression of miR185 inhibits autophagy and apoptosis of dopaminergic neurons by regulating the AMPK/mTOR signaling pathway in Parkinson's disease. Mol Med Rep 17: 131-137, 2018.

24. Son Y, An Y, Jung J, Shin S, Park I, Gwak J, Ju BG, Chung YH, $\mathrm{Na} \mathrm{M}$ and $\mathrm{Oh} \mathrm{S}$ : Protopine isolated from Nandina domestica induces apoptosis and autophagy in colon cancer cells by stabilizing p53. Phytother Res 33: 1689-1696, 2019.

25. Zhang J, Sun M, Hao M, Diao K, Wang J, Li S, Cao Q and Mi X: FAM53A affects breast cancer cell proliferation, migration, and invasion in a p53-dependent manner. Front Oncol 9: 1244, 2019.

26. Wang P, Zhang SD, Jiao J, Wang W, Yu L, Zhao XL, Wang LT, Meng D and Fu YJ: ROS-mediated p53 activation by Juglone enhances apoptosis and autophagy in vivo and in vitro. Toxicol Appl Pharmacol 379: 114647, 2019.

27. Meng J, Li Y, Zhang M, Li W, Zhou L, Wang Q, Lin L, Jiang L and Zhu W: A combination of curcumin, vorinostat and silibinin reverses $A \beta$-induced nerve cell toxicity via activation of AKT-MDM2-p53 pathway. PeerJ 7: e6716, 2019.

28. Xu W, Gao L, Li T, Zheng J, Shao A and Zhang J: Mesencephalic Astrocyte-Derived Neurotrophic Factor (MANF) protects against neuronal apoptosis via activation of Akt/MDM2/p53 signaling pathway in a rat model of intracerebral hemorrhage. Front Mol Neurosci 11: 176, 2018.

29. Ritchie ME, Phipson B, Wu D, Hu Y, Law CW, Shi W and Smyth GK: Limma powers differential expression analyses for RNA-sequencing and microarray studies. Nucleic Acids Res 43: e47, 2015 .

30. The Gene Ontology Consortium: The gene ontology resource: 20 years and still Going strong. Nucleic Acids Res 47: D330-D338, 2019.

31. Ashburner M, Ball CA, Blake JA, Botstein D, Butler H, Cherry JM, Davis AP, Dolinski K, Dwight SS, Eppig JT, et al: Gene ontology: Tool for the unification of biology. The Gene Ontology Consortium. Nat Genet 25: 25-29, 2000.

32. Kanehisa M: Post-genome informatics. Oxford University Press, Oxford, 2000.

33. Huang DW, Sherman BT and Lempicki RA: Systematic and integrative analysis of large gene lists using DAVID bioinformatics resources. Nat Protoc 4: 44-57, 2009.

34. Huang DW, Sherman BT and Lempicki RA: Bioinformatics enrichment tools: Paths toward the comprehensive functional analysis of large gene lists. Nucleic Acids Res 37: 1-13, 2009.

35. Livak KJ and Schmittgen TD: Analysis of relative gene expression data using real-time quantitative PCR and the 2(-Delta Delta C(T)) method. Methods 25: 402-408, 2001

36. Whyte L, Huang YY, Torres K and Mehta RG: Molecular mechanisms of resveratrol action in lung cancer cells using dual protein and microarray analyses. Cancer Res 67: 12007-12017, 2007.

37. Liu F, Gao S, Yang Y, Zhao X, Fan Y, Ma W, Yang D, Yang A and Yu Y: Curcumin induced autophagy anticancer effects on human lung adenocarcinoma cell line A549. Oncol Lett 14: 2775-2782, 2017.

38. Liu F, Gao S, Yang Y, Zhao X, Fan Y, Ma W, Yang D, Yang A and Yu Y: Antitumor activity of curcumin by modulation of apoptosis and autophagy in human lung cancer A549 cells through inhibiting PI3K/Akt/mTOR pathway. Oncol Rep 39: 1523-1531, 2018.

39. Eskelinen EL, Reggiori F, Baba M, Kovacs AL and Seglen PO: Seeing is believing: The impact of electron microscopy on autophagy research. Autophagy 7: 935-956, 2011

40. Cristofani R, Montagnani Marelli M, Cicardi ME, Fontana F, Marzagalli M, Limonta P, Poletti A and Moretti RM: Dual role of autophagy on docetaxel-sensitivity in prostate cancer cells. Cell Death Dis 9: 889, 2018.

41. Liu D, Yang Y, Liu Q and Wang J: Inhibition of autophagy by 3-MA potentiates cisplatin-induced apoptosis in esophageal squamous cell carcinoma cells. Med Oncol 28: 105-111, 2011.

42. Zhang J, Chiu J, Zhang H, Qi T, Tang Q, Ma K, Lu H and Li G: Autophagic cell death induced by resveratrol depends on the $\mathrm{Ca}(2+) / \mathrm{AMPK} / \mathrm{mTOR}$ pathway in A549 cells. Biochem Pharmacol 86: 317-328, 2013. 
43. Li X, Wang D, Zhao QC, Shi T and Chen J: Resveratrol inhibited Non-small cell lung cancer through inhibiting STAT-3 signaling. Am J Med Sci 352: 524-530, 2016.

44. Wang $\mathrm{H}$, Zhang $\mathrm{H}$, Tang L, Chen $\mathrm{H}$, Wu C, Zhao M, Yang Y, Chen X and Liu G: Resveratrol inhibits TGF- $\beta 1$-induced epithelial-to-mesenchymal transition and suppresses lung cancer invasion and metastasis. Toxicology 303: 139-146, 2013.

45. Czarnomysy R, Bielawska A and Bielawski K: Effect of 2nd and 3rd generation PAMAM dendrimers on proliferation, differentiation, and pro-inflammatory cytokines in human keratinocytes and fibroblasts. Int J Nanomedicine 14: 7123-7139, 2019.

46. Yuan X, Nie W, He Z, Yang J, Shao B, Ma X, Zhang X, Bi Z, Sun L, Liang X, et al: Carbon black nanoparticles induce cell necrosis through lysosomal membrane permeabilization and cause subsequent inflammatory response. Theranostics 10: 4589-4605, 2020.

47. Gao J,Zhao Y, Wang C, Ji H, Yu J, Liu C and Liu A: A novel synthetic chitosan selenate (CS) induces apoptosis in A549 lung cancer cells via the Fas/FasL pathway. Int J Biol Macromol 158: 689-697, 2020.

48. Chen S, Cheng AC, Wang MS and Peng X: Detection of apoptosis induced by new type gosling viral enteritis virus in vitro through fluorescein Annexin V-FITC/PI double labeling. World J Gastroenterol 14: 2174-2178, 2008.

49. Feng J, Feng T, Yang C, Wang W, Sa Y and Feng Y: Feasibility study of stain-free classification of cell apoptosis based on diffraction imaging flow cytometry and supervised machine learning techniques. Apoptosis 23: 290-298, 2018.

50. Deng S, Shanmugam MK, Kumar AP, Yap CT, Sethi G and Bishayee A: Targeting autophagy using natural compounds for cancer prevention and therapy. Cancer Am Cancer Soc 125 : 1228-1246, 2019.

51. Klionsky DJ and Emr SD: Autophagy as a regulated pathway of cellular degradation. Science 290: 1717-1721, 2000.

52. Ravikumar B, Moreau K, Jahreiss L, Puri C and Rubinsztein DC: Plasma membrane contributes to the formation of pre-autophagosomal structures. Nat Cell Biol 12: 747-757, 2010.

53. Puissant A and Auberger P: AMPK- and p62/SQSTM1-dependent autophagy mediate resveratrol-induced cell death in chronic myelogenous leukemia. Autophagy 6: 655-657, 2010.

54. Wang M, Yu T, Zhu C, Sun H, Qiu Y, Zhu X and Li J: Resveratrol triggers protective autophagy through the ceramide/Akt/mTOR pathway in melanoma B16 cells. Nutr Cancer 66: 435-440, 2014.

55. Puissant A, Robert G, Fenouille N, Luciano F, Cassuto JP, Raynaud S and Auberger P: Resveratrol promotes autophagic cell death in chronic myelogenous leukemia cells via JNK-mediated p62/SQSTM1 expression and AMPK activation. Cancer Res 70: $1042-1052,2010$

56. Zheng Y, Tu J, Wang X, Yu Y, Li J, Jin Y and Wu J: The therapeutic effect of melatonin on GC by inducing cell apoptosis and autophagy induced by endoplasmic reticulum stress. Onco Targets Ther 12: 10187-10198, 2019.
57. Xiang M, Jiang HG, Shu Y, Chen YJ, Jin J, Zhu YM, Li MY, $\mathrm{Wu} \mathrm{JN}$ and $\mathrm{Li} \mathrm{J}$ : Bisdemethoxycurcumin enhances the sensitivity of Non-small cell lung cancer cells to Icotinib via dual induction of autophagy and apoptosis. Int J Biol Sci 16: 1536-1550, 2020.

58. Shin D, Kim EH, Lee J and Roh JL: RITA plus 3-MA overcomes chemoresistance of head and neck cancer cells via dual inhibition of autophagy and antioxidant systems. Redox Biol 13: 219-227, 2017.

59. Bao Y, Ding Z, Zhao P, Li J, Chen P, Zheng J and Qian Z: Autophagy inhibition potentiates the anti-EMT effects of alteronol through TGF-beta/Smad3 signaling in melanoma cells. Cell Death Dis 11: 223, 2020.

60. Zeng R, He J, Peng J, Chen Y, Yi S, Zhao F and Cui G: The time-dependent autophagy protects against apoptosis with possible involvement of Sirt1 protein in multiple myeloma under nutrient depletion. Ann Hematol 91: 407-417, 2012

61. Zhi L, Song D, Ma L and Feng T: Soyasapogenol B attenuates laryngeal carcinoma progression through inducing apoptotic and autophagic cell death. Anat Rec (Hoboken) 303: 1851-1858, 2020.

62. Park BS, Choi NE, Lee JH, Kang HM, Yu SB, Kim HJ, Kang HK and Kim IR: Crosstalk between Fisetin-induced apoptosis and autophagy in human oral squamous cell carcinoma. J Cancer 10: 138-146, 2019.

63. Zhou J, An X, Dong J, Wang Y, Zhong H, Duan L, Ling J, Ping F and Shang J: IL-17 induces cellular stress microenvironment of melanocytes to promote autophagic cell apoptosis in vitiligo. FASEB J 32: 4899-4916, 2018.

64. Tang ZH, Chen X, Wang ZY, Chai K, Wang YF, Xu XH, Wang XW, Lu JH, Wang YT, Chen XP and Lu JJ: Induction of C/EBP homologous protein-mediated apoptosis and autophagy by licochalcone A in non-small cell lung cancer cells. Sci Rep 6: 26241, 2016.

65. Liu S, Lin H, Wang D, Li Q, Luo H, Li G, Chen X, Li Y, Chen P, Zhai $\mathrm{B}$, et al: $\mathrm{PCDH} 17$ increases the sensitivity of colorectal cancer to 5 -fluorouracil treatment by inducing apoptosis and autophagic cell death. Signal Transduct Target Ther 4: 53, 2019.

66. Ogawara Y, Kishishita S, Obata T, Isazawa Y, Suzuki T, Tanaka K, Masuyama N and Gotoh Y: Akt enhances Mdm2-mediated ubiquitination and degradation of p53. J Biol Chem 277: 21843-21850, 2002.

67. Zhu Y, He W, Gao X, Li B, Mei C, Xu R and Chen H: Resveratrol overcomes gefitinib resistance by increasing the intracellular gefitinib concentration and triggering apoptosis, autophagy and senescence in PC9/G NSCLC cells. Sci Rep 5: 17730, 2015.

68. Luo H, Yang A, Schulte BA, Wargovich MJ and Wang GY: Resveratrol induces premature senescence in lung cancer cells via ROS-mediated DNA damage. PLoS One 8: e60065, 2013.

c) (7) $\Theta$ This work is licensed under a Creative Commons C) Attribution-NonCommercial-NoDerivatives 4.0 International (CC BY-NC-ND 4.0) License. 